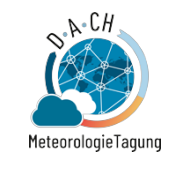

Kurzfassungen der Meteorologentagung DACH

DACH2022-298, 2022

https://doi.org/10.5194/dach2022-298

DACH2022

(C) Author(s) 2022. This work is distributed under

the Creative Commons Attribution 4.0 License.

\title{
Irradiance and cloud optical properties from photovoltaic power data
}

\author{
James Barry ${ }^{1,2}$, Anna Herman-Czezuch ${ }^{1}$, Nicola Kimiaie ${ }^{1}$, Stefanie Meilinger ${ }^{1}$, Christopher \\ Schirrmeister ${ }^{1}$, Johannes Grabenstein ${ }^{2}$, Klaus Pfeilsticker ${ }^{2}$, Claudia Emde ${ }^{3}$, Felix Gödde ${ }^{3}$, Bernhard \\ Mayer $^{3}$, Hartwig Deneke ${ }^{4}$, Jonas Witthuhn ${ }^{4}$, Leonhard Scheck ${ }^{5}$, Marion Schroedter-Homscheidt ${ }^{6}$, \\ Philipp Hofbauer ${ }^{7}$, and Matthias Struck ${ }^{7}$ \\ ${ }^{1}$ Hochschule Bonn-Rhein-Sieg, International Centre for Sustainable Development, Sankt Augustin, Germany (james.barry@h- \\ brs.de) \\ ${ }^{2}$ Institute of Environmental Physics, University of Heidelberg, Heidelberg, Germany \\ ${ }^{3}$ Meteorological Institute, Ludwig-Maximilians-Universität, Munich, Germany \\ ${ }^{4}$ Leibniz Institute for Tropospheric Research, Leipzig, Germany \\ ${ }^{5}$ Hans-Ertel Centre for Weather Research, Munich, Germany \\ ${ }^{6}$ Deutsches Zentrum für Luft- und Raumfahrt, Institut für Vernetzte Energiesysteme, Oldenburg, Germany \\ ${ }^{7}$ egrid applications \& consulting $\mathrm{GmbH}$, Kempten, Germany
}

The rapid increase in solar photovoltaic (PV) installations worldwide has resulted in the electricity grid becoming increasingly dependent on atmospheric conditions, thus requiring more accurate forecasts of incoming solar irradiance. In this context, measured data from PV systems are a valuable source of information about the optical properties of the atmosphere, in particular the cloud optical depth (COD). This work reports first results from an inversion algorithm developed to infer global, direct and diffuse irradiance as well as atmospheric optical properties from PV power measurements, with the goal of assimilating this information into numerical weather prediction (NWP) models.

High resolution measurements from both PV systems and pyranometers were collected as part of the BMWi-funded MetPVNet project, in the Allgäu region during autumn 2018 and summer 2019. These data were then used together with a PV model and both the DISORT and MYSTIC radiative transfer schemes within libRadtran (Emde et al., 2016; Mayer and Kylling, 2005) $\square$ to infer cloud optical depth as well as direct, diffuse and global irradiance under highly variable atmospheric conditions. Hourly averages of each of the retrieved quantities were compared with the corresponding predictions of the COSMO weather model as well as data from satellite retrievals, and periods with differing degrees of variability and different cloud types were analysed. The DISORTbased algorithm is able to accurately retrieve COD, direct and diffuse irradiance components as long as the cloud fraction is high enough, whereas under broken cloud conditions the presence of 3D effects can lead to large errors. In that case the global horizontal irradiance is derived from tilted irradiance measurements and/or PV data using a lookup table based on the MYSTIC 3D Monte Carlo radiative transfer solver (Mayer, 2009) $\square$. This work will provide the basis for future investigations using a larger number of PV systems to evaluate the improvements to irradiance and power forecasts that could be achieved by the assimilation of inferred irradiance into an NWP model. 


\section{References}

Emde, C., Buras-Schnell, R., Kylling, A., Mayer, B., Gasteiger, J., Hamann, U., Kylling, J., Richter, B., Pause, C., Dowling, T. and Bugliaro, L.: The libRadtran software package for radiative transfer calculations (version 2.0.1), Geosci. Model Dev., 9(5), 1647-1672, doi:10.5194/gmd-9-1647-2016, 2016.

Mayer, B.: Radiative transfer in the cloudy atmosphere, EPJ Web Conf., 1, 75-99, doi:10.1140/epjconf/e2009-00912-1, 2009.

Mayer, B. and Kylling, A.: Technical note: The libRadtran software package for radiative transfer calculations - description and examples of use, Atmos. Chem. Phys., 5(7), 1855-1877, doi:10.5194/acp-5-1855-2005, 2005. 